OPEN ACCESS

Edited by: Jaap Kaandorp,

University of Amsterdam, Netherlands

Reviewed by:

Juan Pablo Carricart-Ganivet, Universidad Nacional Autónoma de

Mexico, Mexico

Aldo Cróquer,

Simón Bolívar University, Venezuela

*Correspondence:

Emmanuel G. Reynaud emmanuel.reynaud@ucd.ie

Specialty section: This article was submitted to

Coral Reef Research,

a section of the journa

Frontiers in Marine Science

Received: 07 March 2018

Accepted: 20 July 2018

Published: 21 August 2018

Citation:

Gutierrez-Heredia L, Keogh C and Reynaud EG (2018) Assessing the

Capabilities of Additive Manufacturing

Technologies for Coral Studies,

Education, and Monitoring.

Front. Mar. Sci. 5:278.

doi: 10.3389/fmars.2018.00278

\section{Assessing the Capabilities of Additive Manufacturing Technologies for Coral Studies, Education, and Monitoring}

\author{
Luis Gutierrez-Heredia $^{1}$, Colin Keogh ${ }^{2}$ and Emmanuel G. Reynaud ${ }^{1 *}$ \\ ${ }^{1}$ School of Biomolecular \& Biomedical Science, UCD Science Centre, Dublin, Ireland, ${ }^{2}$ School of Mechanical and Materials \\ Engineering, UCD Engineering and Materials Science Centre, Dublin, Ireland
}

Additive manufacturing, better known as 3D printing is becoming an easily accessible method to produce 3D objects ranging from medical devices to jet plane parts. However, this implies the creation of an accurate 3D digital model by Computer Assisted Design (CAD) or direct acquisition of a 3D model as well as a correct understanding of the various 3D printing technologies available with their pros and cons. Here, we present a method for editing and printing of 3D models of coral colonies for the generation of accurate and enhanced 3D models suitable for research and education. This is a follow-up from other papers where 3D scanning was performed on fresh coral samples from field trips and coral skeletons from museum collections using different imaging techniques (multi-image photogrammetry and Micro CT scanning). 3D scans of colonies and samples of Turbinaria sp., Leptoseris incrustans, Oulophyllia crispa, Echinopora sp., Siderastrea savignyana, and Platygira daedalea were used to produce multi-material and multi-scale 3D prints. Moreover, we studied the best practices for the 3D printing processes, and potential technologies most suitable for specific attributes in this practice. Additionally, we show the innovative application of 3D printed inert reactive corals able to indicate environmental changes, along with insights into the potential uses for the proposed method and related systems in biological fields and sharing with an online community.

Keywords: 3D modelling, 3D printing, corals, scleractinia, photogrammetry, additive manufacturing, education

\section{INTRODUCTION}

Since their introduction in the 1980s 3D Printing (3DP) systems have rapidly become highly effective tools for a broad range of applications in a wide number of fields. The technology was firstly developed in the Nagoya Municipal Industrial Research Institute by Hideo Kodama who proposed an account of a rapid prototyping systems utilising photopolymer curing processes (Kodama, 1981). The technology has matured since and has seen a huge growth in popularity, complexity, speed, variety of materials employed and potential areas of application (Fredieu et al., 2015). The term "3D Printing" is used to describe many rapid prototyping systems, all of which operate under the basic principle of the controlled consecutive layering of a material to generate complex $3 \mathrm{D}$ structures.

There are many methods which fall under the classification of 3DP, with the main differentiating factor being the process in which the individual layers are formed to produce a completed 
part, model, or object. Some of the most versatile and widely used 3DP technologies are Fused Deposition Modelling, (FDM), Stereolithography (SLA), Laminated Object Manufacture (LOM), and Blinder Jet. The use of such 3DP systems has found numerous applications in a wide range of fields, from purely scientific pursuits in the medical, engineering, design and biology fields through to more artistic endeavours in the fashion and artistic sectors.

The most frequently adopted and popularised uses of these 3DP techniques have been in medicalscience, particularly for the prototyping and implantation of replacement parts for the human body (Gerstle et al., 2014) and for pre-operative planning of surgeries, using collected CT and MRI scan data to reconstruct 3D models of complex internal structures (McGurk et al., 1997; Rengier et al., 2012; Klein et al., 2013). Use in other biological-based fields has included the replication of physical representations of molecules in biomolecular sciences (Jones, 2012) and the documentation and restoration of artefacts in the paleontological and archaeological fields (Kuzminsky and Gardiner, 2012). These applications have been focused on education and training for both the general public and specialised users (surgeons, archaeologists, etc.) and have helped improve the overall value of education (Eisenberg and Buechley, 2008; Eisenberg, 2013; Fredieu et al., 2015), science visualization (Partridge et al., 2012; Segerman, 2012) and science outreach to the public in museum and exhibition contexts (Allard et al., 2005; Tomaka et al., 2009; Wachowiak and Karas, 2009; Chapman et al., 2010). 3DP has recently been used in coral studies as physical models in hydrodynamic simulations in flow chambers (Chindapol et al., 2013) and to produce customised cement and sandstone blocks in artificial coral reef restoration (Kramer et al., 2016).

It has been demonstrated that, by using diverse imaging methods,3D models can be produced in both field and laboratory conditions for diverse morphologies of coral colonies and corallites at multi-scale levels from both fresh samples and skeleton collections (Gutierrez-Heredia et al., 2015, 2016). Some widely available $3 \mathrm{D}$ digitising methods are laser triangulation, multi-image photogrammetry, CT scanning, and structuredlight scanning. 3D models produced by these methods are suitable for the accurate calculation of biological parameters and can digitise different physical properties such as multiimage photogrammetry to capture superficial texture mapping and colouring, and CT scanning to represent internal structures. These digital collections are ideal for CAD modification to $3 \mathrm{D}$ printing tests as each $3 \mathrm{D}$ model can be adapted to fit the particular printing technology that can best represent different biological characteristics (form, texture, and colour) and distinct material properties (density, endurance, and reactiveness) for handling in education and training, and as customised tools for research.

\section{MATERIALS AND METHODS}

\section{Imaging and Modelling}

A 3D model of Turbinaria sp. was digitized using multiimage photogrammetry according to Gutierrez-Heredia et al.
(2015), (Figure 1), and 3D models of samples and corallites of Oulophyllia crispa, Leptoseris incrustans, and Platygyra daedalea were similarly digitized using this technique as mentioned in Gutierrez-Heredia et al. (2016), (Figure 2). Siderastrea savignyana and Echinopora sp. corallites were imaged from small pieces extracted from bleached coral skeleton samples cut into small sections to fit inside the Micro CT scanner. S. savignyana was cut into a rectangular prism $(21 \times 6 \times 5 \mathrm{~mm})$ and Echinopora sp. was cut into a rectangular prism $(13 \times 5 \times 4 \mathrm{~mm})$. These samples were secured in Polyurethane foam and scanned with a CT120 (Trifoil Imaging) Micro-CT scanner. The micro-CT image acquisition consisted of 1,200 projections taken at $0.3^{\circ}$ increments in one full rotation of the gantry in $\sim 40$ min with an exposure of $100 \mathrm{~ms}$ and bin mode $1 \times 1$. The $\mathrm{X}$-ray tube voltage current was $80 \mathrm{kV}$ and $32 \mu \mathrm{A}$, respectively. The resulting raw data were reconstructed using customised proprietary software to create a final image with $25 \mu \mathrm{m}$ voxel dimensions. MicroView (ABA 2.4 General Electric) software was used to crop and 99 rotate images to isolate the area of interest and the images were converted to DICOM format. The DICOM files were transferred to a desktop computer iMac Quad-Core 2.7 GHz Intel Core i5 with 8 GB RAM with OS X Lion 10.7.3, and processed with the free open-source version of the imaging software OsiriX (Pixmeo) v. 5.9 (32-bit). These were surface-rendered in the highest resolution values possible for closest fit to threshold between specimen density without generating artifacts from the holding foam for isosurface generation to export the resulting 3D models as stereolithography (.stl) format files. These models were then imported into freeware Meshmixer (64-bit, v2.4) to remove odd artefacts and background noise and for the segmentation of one corallite of interest.

\section{Specimen Replication}

The resulting digital specimens were utilised for $3 \mathrm{D}$ printing applications to allow for their physical replication. These stereolithography files, both from photogrammetry and MicroCT Scanning, were imported into Cura 3D slicing software (version 13.04) to generate the individual printing slices, paths, or patterns. Models were scaled and orientated accordingly and then printed using a variety of 3DP methods. Fused Deposition Modelling (FDM), Stereolithography (SLA), Laminated Object Manufacture (LOM), and Binder Jet printing methods were used, with details discussed below.

\section{Fused Deposition Modelling (FDM)}

A range of Ultimaker FDM 3DP's (Ultimaker Original 2 \& 3), were employed to produce prints of the coral models. Three millimeters of Ultimaker \& Ink3D Polylactic acid (PLA) \& Acrylonitrile butadiene styrene (ABS) polymer filaments were used in colours silver, white, and clear blue, to reproduce the generated model. Models were scaled and orientated in an upright position and then printed using base parameters with a fill density of $5-15 \%$, external support material only and printed on a raft for stability. These slices were then compiled and exported as a G-code file to be printed on the printers listed above. 


\section{Stereolithography (SLA)}

A Form1+ SLA printer (Formlabs) was used to produce prints of the generated models. A clear UV cure resin (Formlabs) was used, giving a semi opaque reproduction of the model. A 3D model of Turbinaria sp. was printed in translucent resin using a Formlabs Form 1+ printer, which uses the SLA method
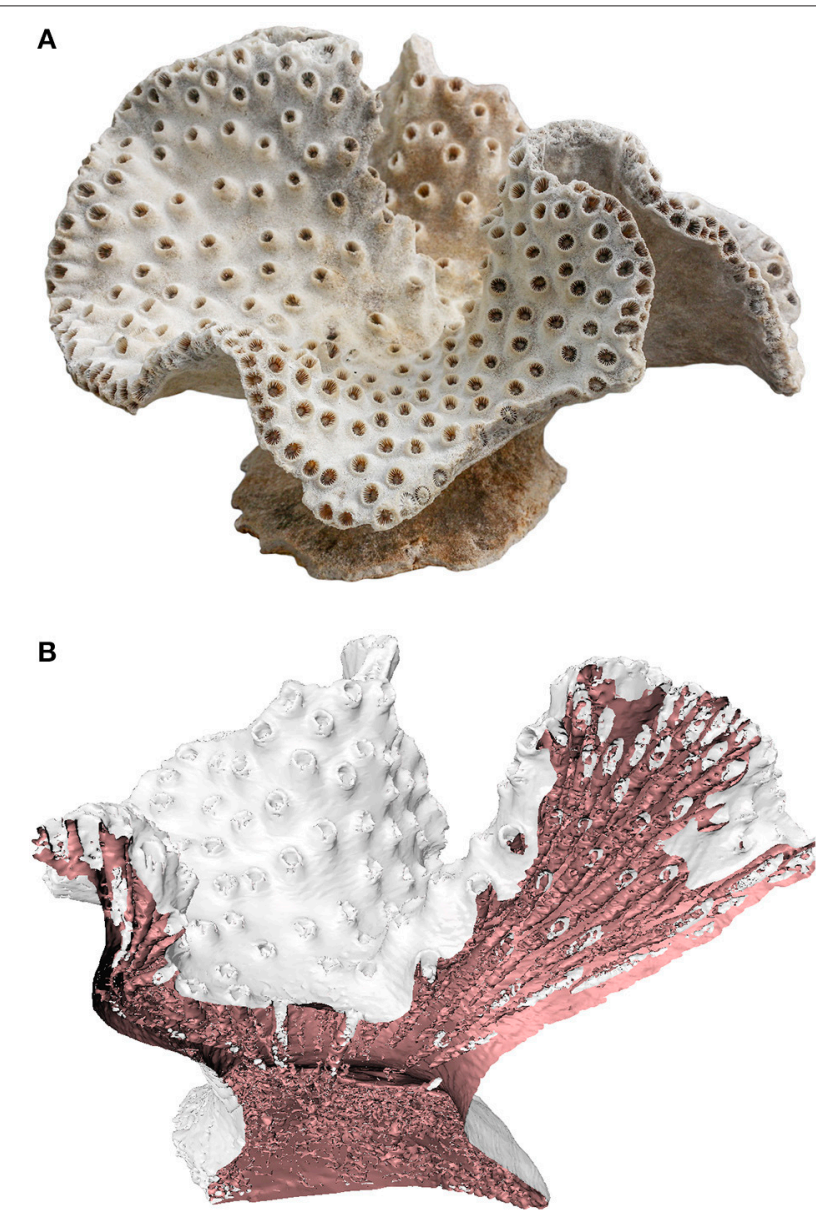

FIGURE 1 | (A) Turbinaria sp. colony (B) 3D model generated by CT Scanning (Gutierrez-Heredia et al., 2015).

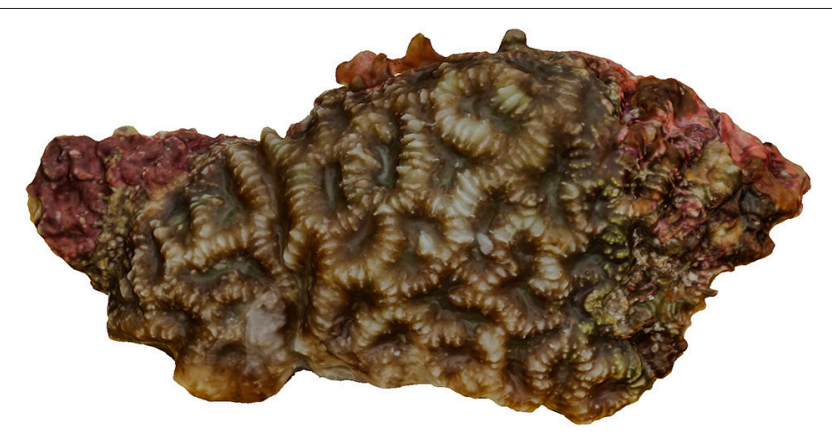

FIGURE 2 | Full colour 3D model of Platygira daedalea colony generated from a fresh sample (Keaveney et al., 2016). of 3DP. The matching Formlabs slicing software, Preform, was used with a model layer thickness of 25 microns. The resin used with the Form 1 is a photoreactive resin classed as a mixture of methacrylic acid esters and photo initiator. Its formulation is proprietary, but it contains methacrylated oligomers, methacrylated monomers, and an unknown photo initiator. It cures at $405 \mathrm{~nm}$ wavelength and the Form1 uses a laser light source directed by a galvanometer to cure the desired pattern per layer. Formlabs software (Preform) was used to orientate, hollow, and support the part for printing.

\section{Laminated Object Manufacture (LOM)}

An M-COR Iris (produced by M-Cor Technologies) was used to produce a LOM print of one of the generated models (Figure 3). Standard 100-micron printing paper was used, along with standard office printing ink to give a full colour reproduction of the model. LOM processes present significant opportunities in the biological sciences due to their ability to produce full-colour prints in a safe eco-friendly manner through the use of paper, inks and water based glues.

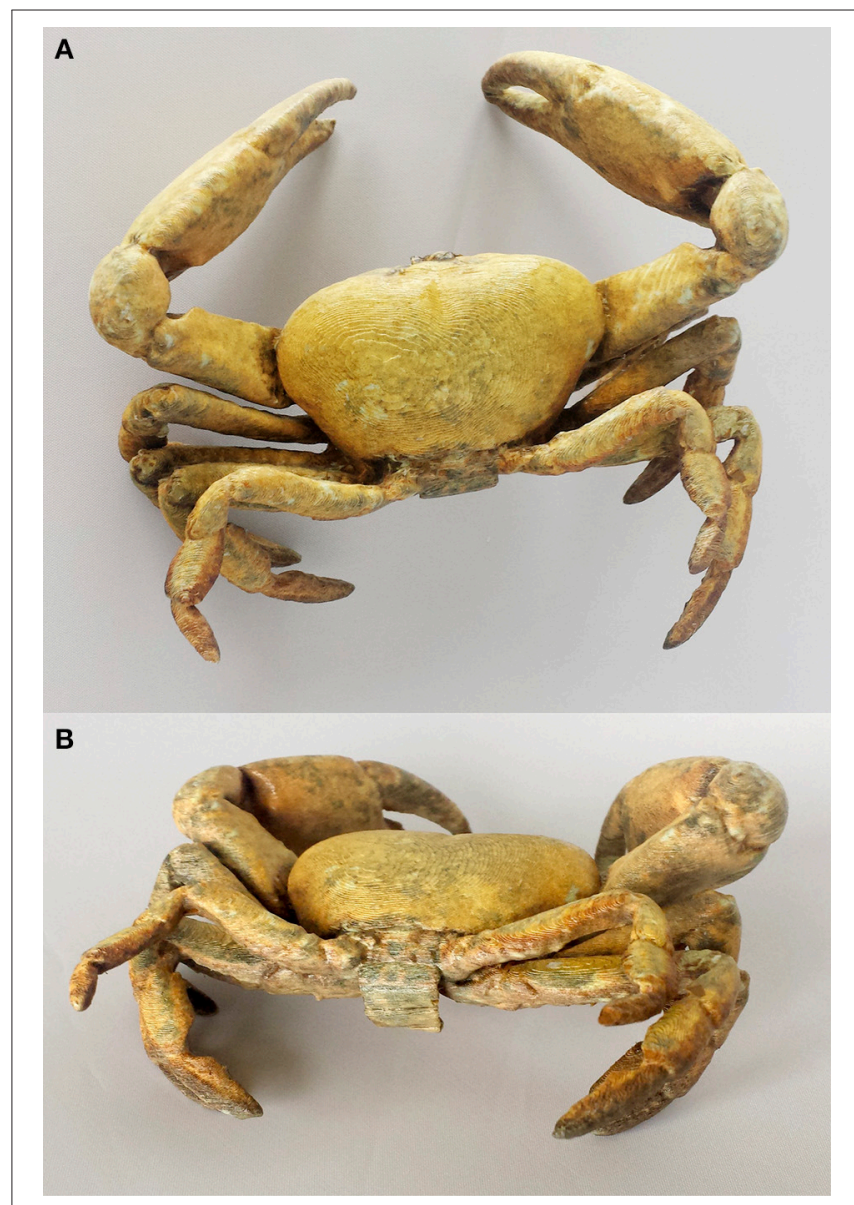

FIGURE 3 | 3D Printed paper model of Segozancia sp. crab (Keaveney et al., 2016). (A) Dorsal view (B) Caudal view. 


\section{Binder Jet}

A 3D model of an O. crispa corallite model was printed in a sandstone colour printer by Shapeways on a Z Printer 3D inkjet printer using VisiJet PXL Core/zp151 material. This process utilises inkjet printing heads to apply a liquid bonding agent to powder material and uses the same layering process to produce the completed part. This process allows the cheap full-colour replication of digital specimens in a range of materials, but due to the powder binding process the parts can have some material mechanical limits.

\section{RESULTS}

Several 3D prints were produced from multi-scale models from coral colonies and corallites in multi-material prints. Varied materials had distinct strengths and weaknesses in physical attributes and detail. When $3 \mathrm{D}$ printing fails to produce details at a certain scale, increasing the resolution of the $3 \mathrm{D}$ model produces an increment in detail of the desired characteristics. In Figure $4 \mathbf{b}$, the $3 \mathrm{D}$ print of $L$. incrustans colony sample shows the morphology of the colony and a number of corallites can be observed individually, while characteristics of corallite septa, costae, and mouths can be observed in the amplification of individual corallites (Figure 4d).

As can be observed in Figure 5, the quality of the $3 \mathrm{D}$ prints from the $3 \mathrm{D}$ model is reduced if this is digitised in very high resolution. Different materials can produce varying degrees of detail in each scale, with varying structural strength and texture of the 3D model. Even different colours of the same material can produce striking differences in detail, due to the influence of light, shadow and colour on the parts. Figure 5 shows the impact of colour and material on the quality and detail of printed objects. Figure 5A shows the digitised $3 \mathrm{~d}$ model, with Figures $5 \mathrm{~B}-\mathrm{F}$ showing a variety of materials and colours giving varying levels of detail and resolution. Silver PLA consistently produced better definition than the other materials, both for colony and corallite scales.

The Turbinaria sp. model was similarly printed below using FDM, BJ, and SLA printers, in a range of colours (Figure 6). The silver PLA printed specimen (Figure 6E) shows the best feature definition, due to its grey colour, allowing the corallites to be clearly seen. The alternative colours, Blue (Figure 6C), White (Figure 6D) \& Black (Figure 6F), are great additions for improved engagement \& education activities, allowing custom colours and materials to enhance the experience. The SLA process allows the production of clear models (Figure 6G) for specialised marine education and the production of a new generation of education tools (such as visualisation of corallite growth inside the colony as imaged by CT scanning).

The segregation and separation of individual biological features or structures allows for high quality replication of fine details. Corallites can be separated and printed on a large scale in a variety of colours to show individual structures and layouts to enhance feature identification. Such small features would not be visible on a full coral print, so the replication of these individual sections allows more information to the imparted to the user. Replication of these corallites can be seen in Figure 7. Detail is high enough to observe the geometry of the corallite wall, number, arrangement and configuration of septa, and texture of the coenosarc, essential for taxonomic identification and other biological studies of scleractinia. Details and the definition of the prints were constantly greater when using Silver PLA on both corallite models.
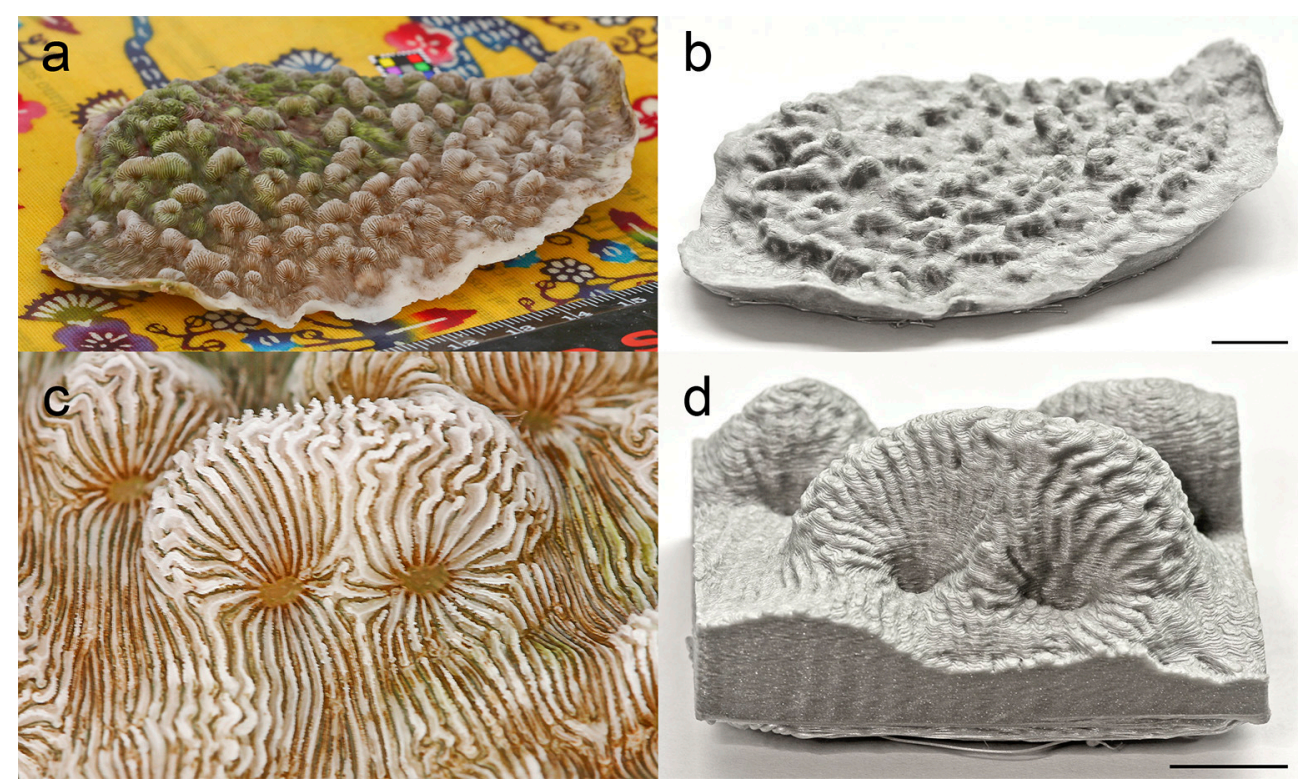

FIGURE 4 | Multi-scale 3D printing of Leptoseris incrustans colony and corallites. (a) Image used in 3D digitisation of colony sample. (b) Silver PLA print of colony sample. (c) Image used for 3D digitisation of corallites. (d) Silver PLA print of corallites. Scale bar represents $1 \mathrm{~cm}$. 

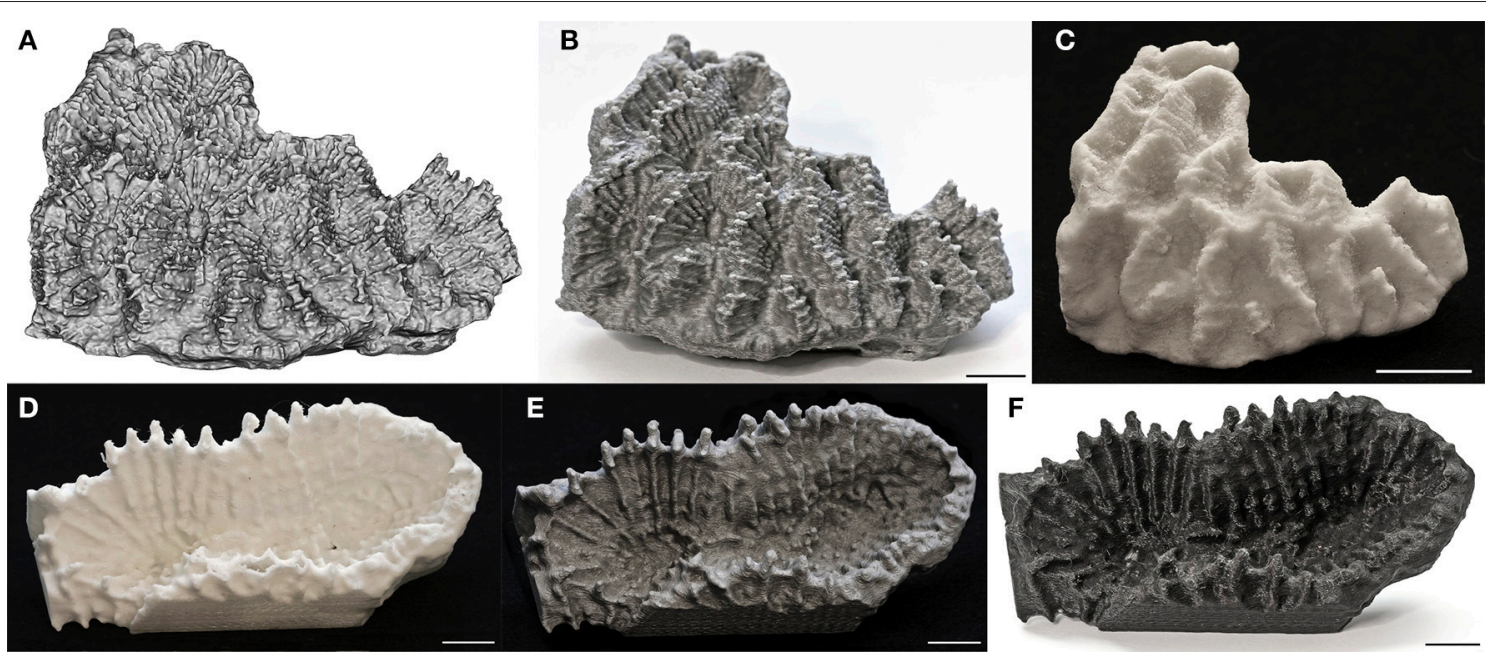

FIGURE 5 | Multi-material and multi-scale 3D printing of Oulophyllia crispa colony and corallites. (A) 3D digital model of colony sample using multi-image photogrammetry. (B) Silver PLA print of colony sample. (C) Sandstone print of colony sample. (D) White PLA print of corallites. (E) Silver PLA print of corallites. (F) Black PLA print of corallites. Scale bar represents $1 \mathrm{~cm}$.

The painting of objects with commercial paints, resins, or varnishes, to produce composite effects can further enhance the display of 3D models. In Figure 8, detailed texturing and shading can be observed in $3 \mathrm{D}$ prints resulting in added contrast in the septa, and mouths of each corallite Furthermore, the use of UV-reacting varnish depicts the autofluorescence quality of the Symbiodinium sp. symbionts that are present in this species. These additions enhance the educational aspects of these models, allowing the mimicking of natural effects such as autofluorescence.

Larger-scale prints can be produced using the paper-based LOM processes, which produce objects using colour printed and layered paper. This process produces large-scale specimens of coral structures with significant weight and density. The full colour printing aspect allows the printing of coral structures in various stages of life, from living coral through corals recently removed from the oceans to fully bleached coral skeletons. This adds a new dimension to the education and engagement process, without the need for the creation of expensive and timeconsuming artist-created models. An example of a 3D paper printed living coral specimen can be seen in Figure 9, produced for Keaveney et al. (2016).

\section{Built-In Functionality}

As a digital specimen is produced, a new range of options becomes available for the further educational enhancement of these models. 3D design software was used to produce $3 \mathrm{D}$ prints with composite elements, accentuation of anatomic features, inbuilt functionality and the production of prints from scratch. In Figure 10a, the corallites of a 3D model of a Turbinaria sp. colony were accentuated and detached from the main model, so composite polymers could be printed. The PLA polymer was the base of the coral skeleton, and an UV-reactive PLA polymer was used for the corallite elements. Figure 10b shows the completed coral model, with Figure 10c showing the corallites reacting when exposed to UV light (direct exposure to sunlight), producing a colour change from light grey to dark purple.

For educational purposes an idealised model of a corallite and polyp were generated using 3D design software (Sketchup, 2016 ${ }^{1}$ ), the assembled parts being produced using different materials (Figure 10d). The polyps demonstrated high detail in morphology, tentacle number and gastric cavity and could be detached from the corallite base to demonstrate the septum number and arrangement, and the central columella. This ability to add or highlight selected elements and build in functionality allows improved education and outreach outcomes, via low cost production methods.

Customised and designed functionality is an added potential benefit from producing these objects with 3DP. New polymer materials are coming on the market which allow enhanced functionality, such as temperature-affected colour changes, (thermochromic filaments) and UV light-affected colour changes, (photochromic filaments). Figures 11a,b show a photochromic coral colony printed with a photochromic filament, transitioning from a white colour to a purple colour in the presence of UV light, similarly Figures 11c,d show 3D fish skeleton models printed with assorted thermochromic filaments, changing colour when subjected to a temperature change.

Similarly, when a digital specimen is generated, the contrast and colouring of the specimen can be altered before printing to allow the highlighting or marking of specific features on the specimen to aid in identification, education, and research activities. This allows the user to tailor the visual characteristics of the printed part to aid in the education process, as seen in Figure 12, in which the texture map is changed to modify the visual characteristics.

\footnotetext{
${ }^{1}$ https://www.sketchup.com/
} 


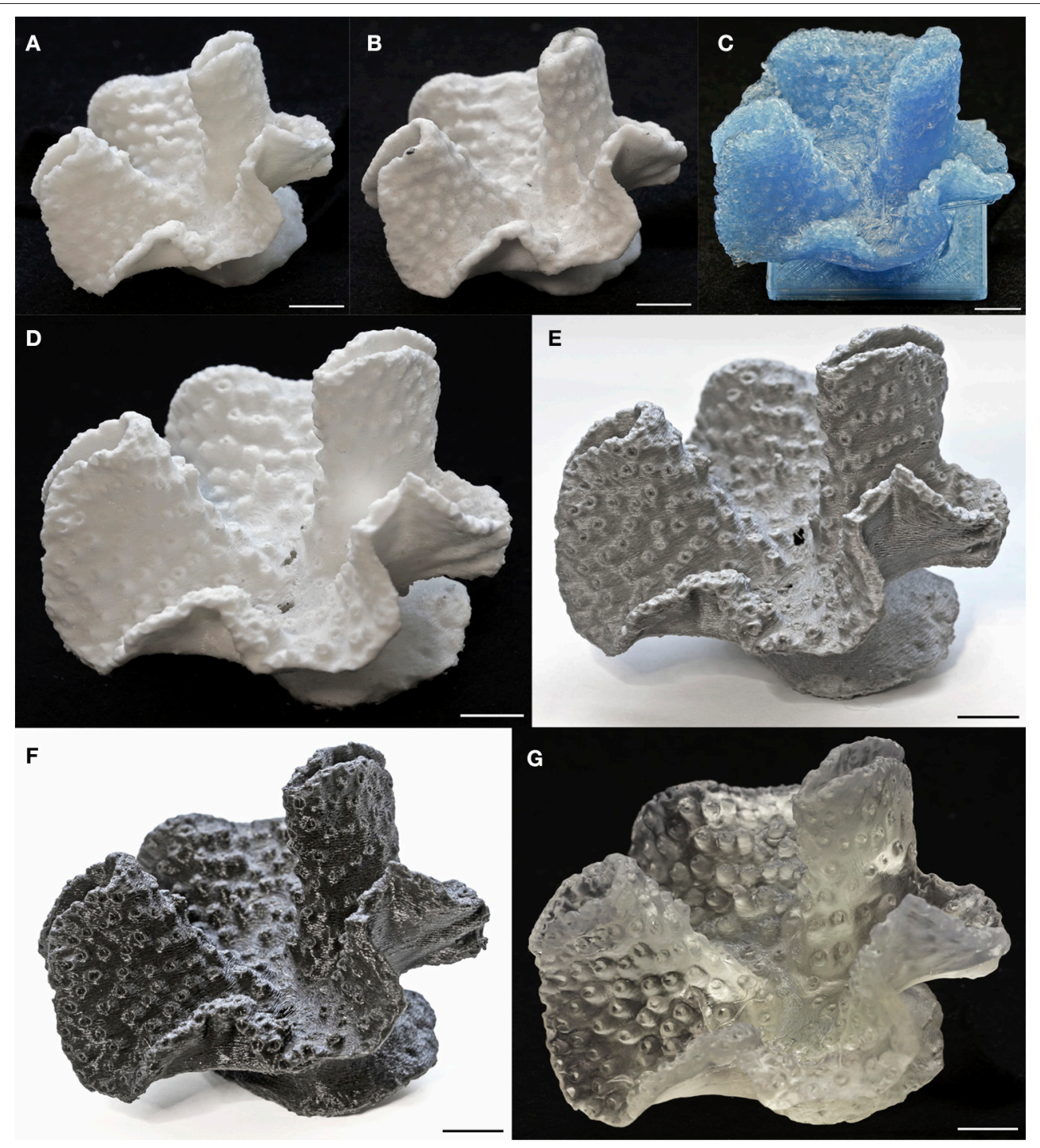

FIGURE 6 | Multi-material 3D printing of Turbinaria sp. colony. (A) White ABS print of colony. (B) Sandstone print of colony. (C) Blue PLA print of colony. (D) White PLA print of corallites. (E) Silver PLA print of colony. (F) Black PLA print of colony. (G) Translucent resin print of colony. Scale bar represents $1 \mathrm{~cm}$.

In addition to the objects themselves, new tools for coral research and data collection can be produced, allowing the creation of customised data collection systems. These systems can be produced at low cost, in remote locations and in short timeframes, allowing the infield repair or modification of parts and systems. An example of a 3D printed UV torch and camera stabiliser unit in use in the field can be seen in Figure 13.

\section{DISCUSSION}

Stereolithography (SLA) and Fused Deposition Modelling (FDM) were constantly used due to their individual advantages and suitability for the context in question. SLA processes are well suited to these applications due to their fine feature resolution, high quality details, surface finish, and favourable optical properties. This method also allows the production of extremely complex geometries, due to the added support from resin and the bottom-up layering process, which is very beneficial for the production of such complex biological specimens. SLA processes require strict control of the level, environment and properties of the print area, along with specific handling \& costs issues associated with the resins required. These requirements make SLA a relatively complex and delicate process, requiring higher levels of control and resulting in higher costs. The FDM process is much simpler, producing low-cost, robust objects with fewer environmental constraints when compared to SLA. The simpler nature and lack of specific environmental conditions results in it being generally much cheaper and easier to use, with significantly lower barriers to entry and utilisation. These FDM processes can exploit a wide range of polymer materials, 

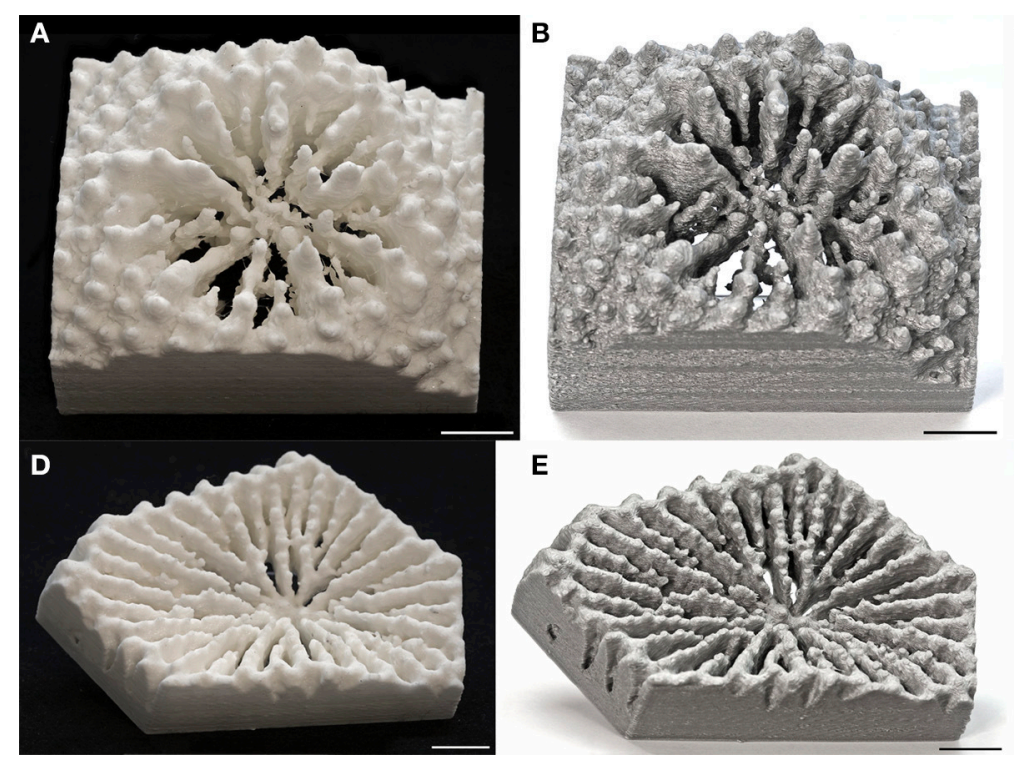

FIGURE 7 | Multi-material 3D printing of Echinopora sp. and Siderastrea savignyana skeletal corallites from MicroCT scanning imaging. (A) White PLA print of Echinopora sp. corallite. (B) Silver PLA print of Echinopora sp. corallite. (C) Black PLA print of Echinopora sp. corallite. (D) White PLA print of S. savignyana corallite (E) Silver PLA print of S. savignyana corallite. (F) Black PLA print of S. savignyana corallite. Scale bar represents $1 \mathrm{~cm}$.

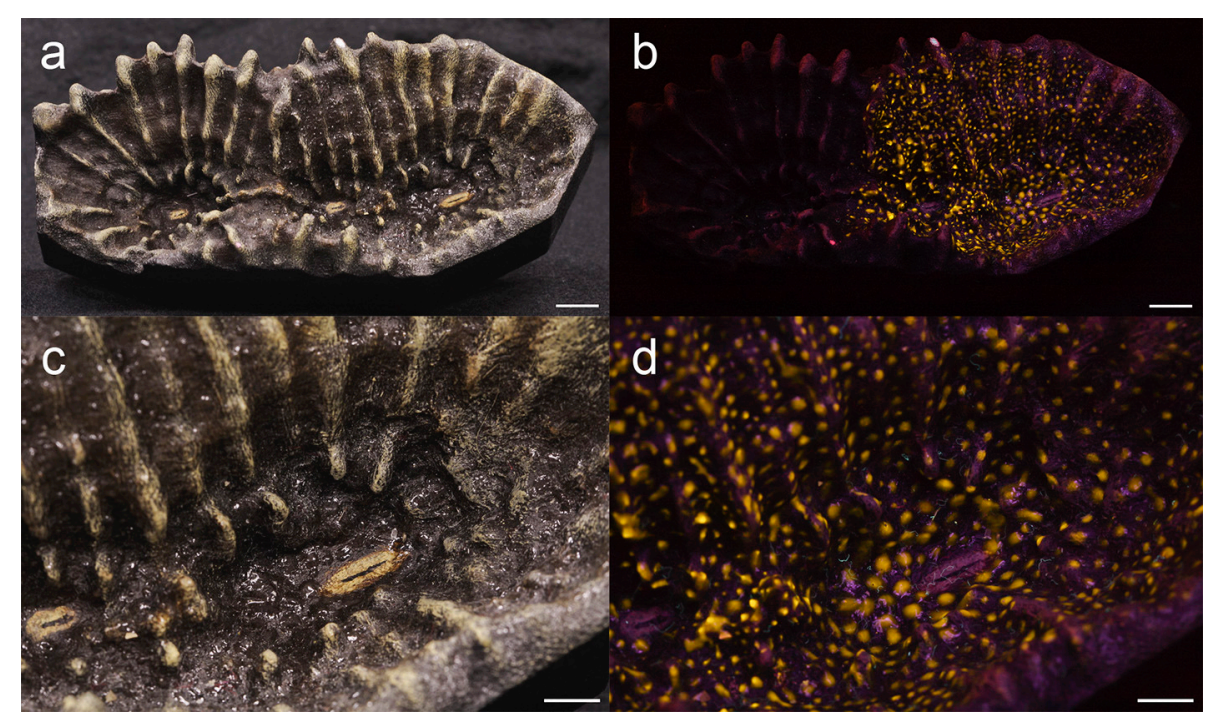

FIGURE 8 | Multi-spectral print of Oulophyllia crispa corallites. (a) Sandstone print of corallites texturised with model paint and UV reactive varnish under normal lighting. (b) Sandstone print of corallites texturised with model paint and UV reactive varnish under UV lighting. Scale bars represent $1 \mathrm{~cm}$. (c) Close-up of sandstone print of corallites texturised with model paint and UV reactive varnish under normal lighting. (d) Close-up of sandstone print of corallites texturised with model paint and UV reactive varnish under UV lighting. Scale bars represent $5 \mathrm{~mm}$.

with almost any thermoplastic and composite materials being of particular interest. These composite materials are usually a mix of thermo-plastic as either a binder, with fibre additions like carbon fibre, or as a carrier, such as those utilising metal powders which can be fused using an oven-based sintering process. The ability to add specific elements to the polymer materials unlocks the potential to tailor specific material performance characteristics on bulk material terms or even to specific parts, components or regions in a print. While these benefits make FDM cheaper, quicker and more accessible than SLA systems, in general FDM processes produce parts with much lower resolutions and much rougher surface finishes than aforementioned SLA systems. The LOM method shows promise for specimen replication for public display, interaction, and engagement activities in the biological sciences leading to increased awareness and public/expert knowledge due to the incredible accuracy of the 

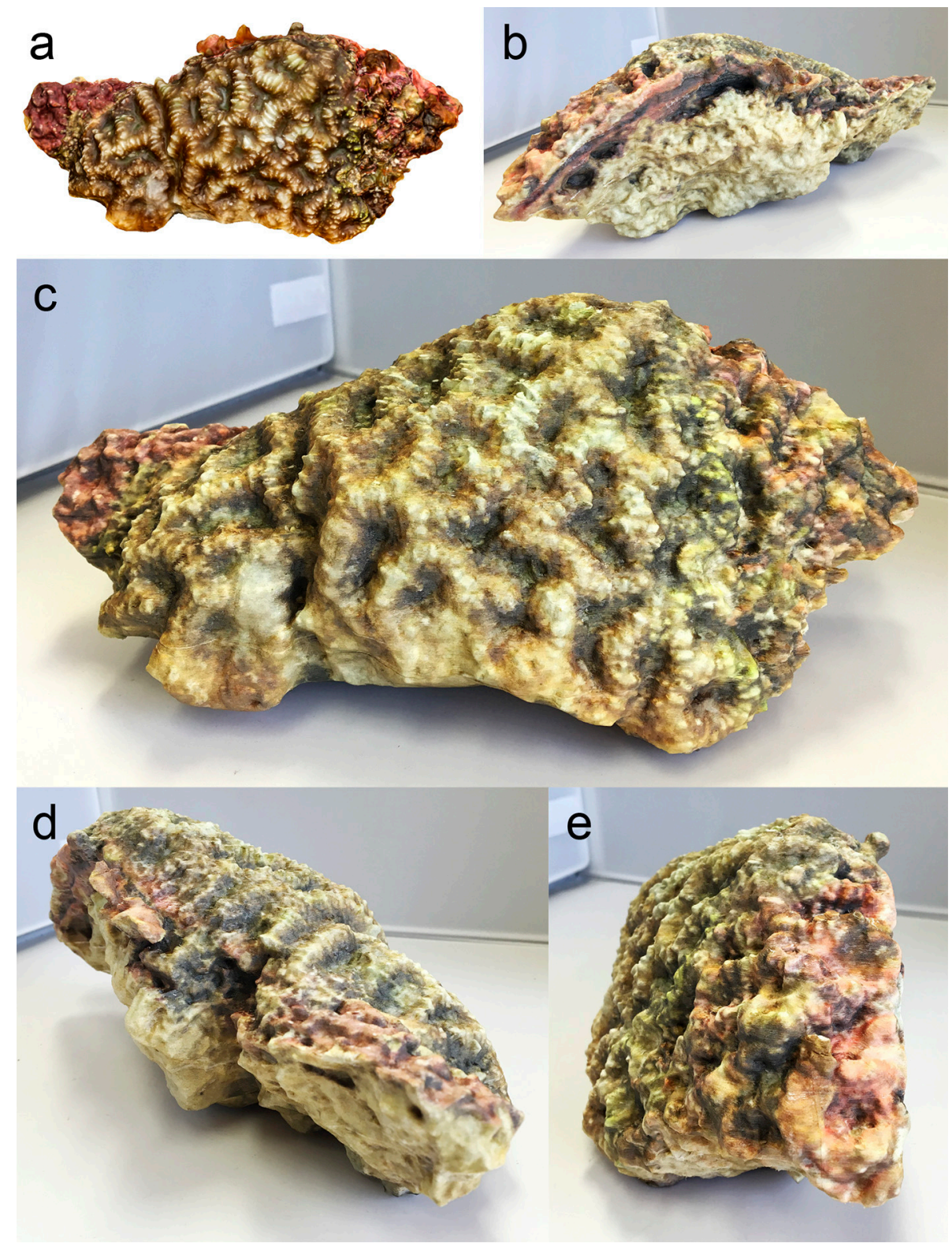

FIGURE 9 | Paper 3D printer Platygira daedalea colony sample with living tissue texture map (Keaveney et al., 2016). (a) Digital 3D model of $P$. daedalea (b) Back view of paper model (c) Front view of paper model (d) Right view of paper model (e) Left view of paper model.

texture recreation from the digital specimen. Finally, the Binder Jet process may have mechanical performance limits due to the hands-on nature of the proposed interactions with the objects.

All of these 3DP methods are widely available, accessible, low cost methods of $3 \mathrm{D}$ printing, which allow the adoption of the proposed replication process in number of cost-sensitive fields. This uncomplicated production of printed parts for use in the classroom or other educational environments allows increased personal engagement with the specimens without any risk to the original samples. These highlighted applications of the proposed concepts \& methodologies show the scope and potential presented in this field. The use of $3 \mathrm{D}$ printing technologies has directly impacted the coral and marine fields in several ways, including the production of cement and sandstone blocks for artificial coral reef restoration (Kramer et al., 2016). It has been noted that scleractinian planulas are naturally drawn to surfaces with pastel colours (particularly white and pink) with a similar texture to coral as potential locations for settling. The planulas also seem inclined to settle on complex $3 \mathrm{D}$ structures with numerous interstices and high rugosity to escape from predators or to avoid being crushed. 3DP technologies are optimal for producing artificial habitats that mimic these characteristics. The neutral $\mathrm{pH}$ of sandstone 

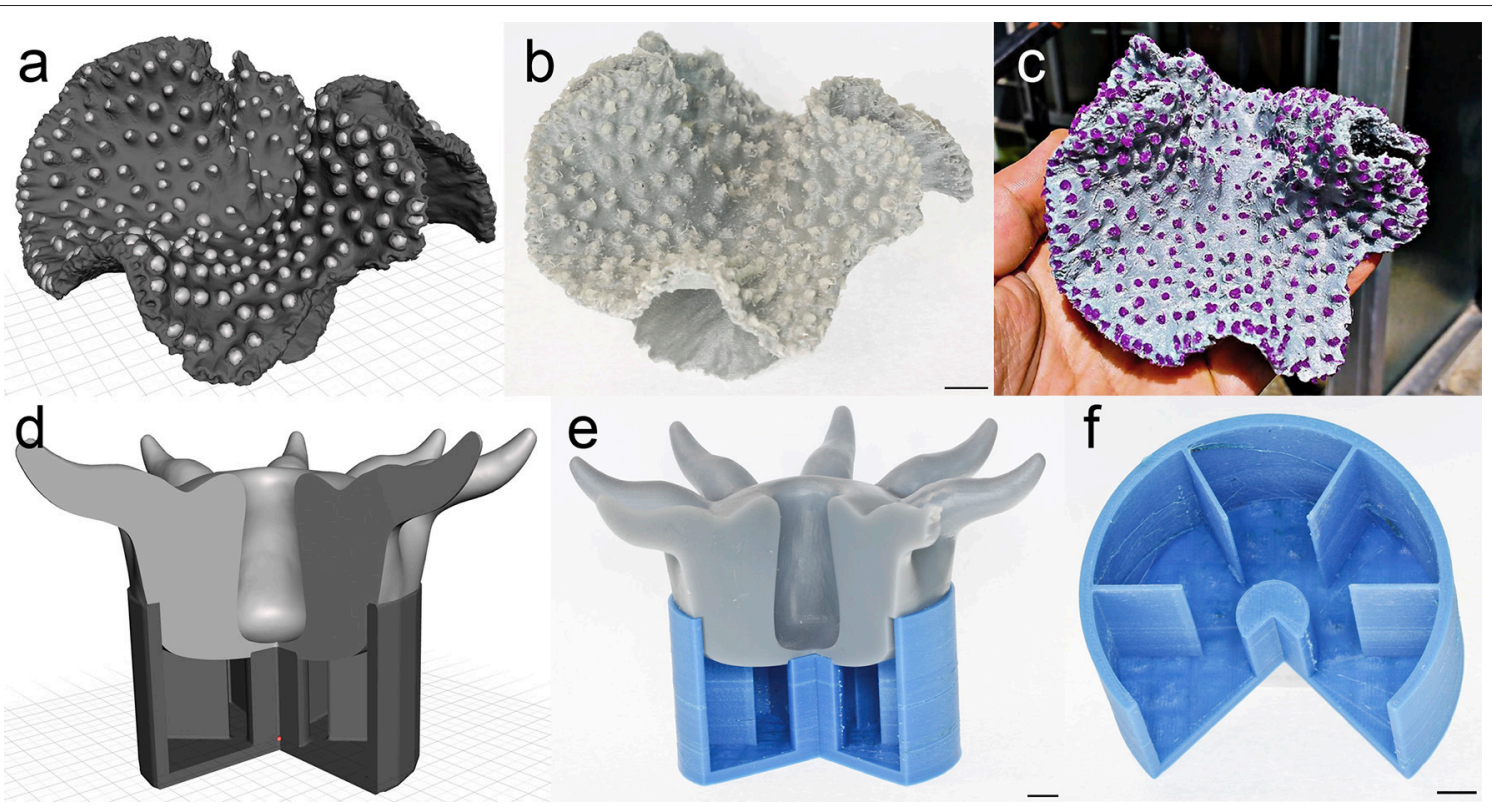

FIGURE 10 | CAD design in the aid of 3D coral printing for sensing research and education. (a) 3D model of Turbinaria sp. colony from laser triangulation imaging for corallite inclusion by design. (b) Silver PLA print of Turbinaria sp. colony with UV reactive PLA corallites. (c) Silver PLA print of Turbinaria sp. colony with UV reactive PLA corallites under direct sunlight. (d) 3D model of idealised corallite theca and polyp for education purposes. (e) PLA print of assembled corallite theca and polyp. (f) PLA print of corallite theca showing septa. Scale bars represent $1 \mathrm{~cm}$.

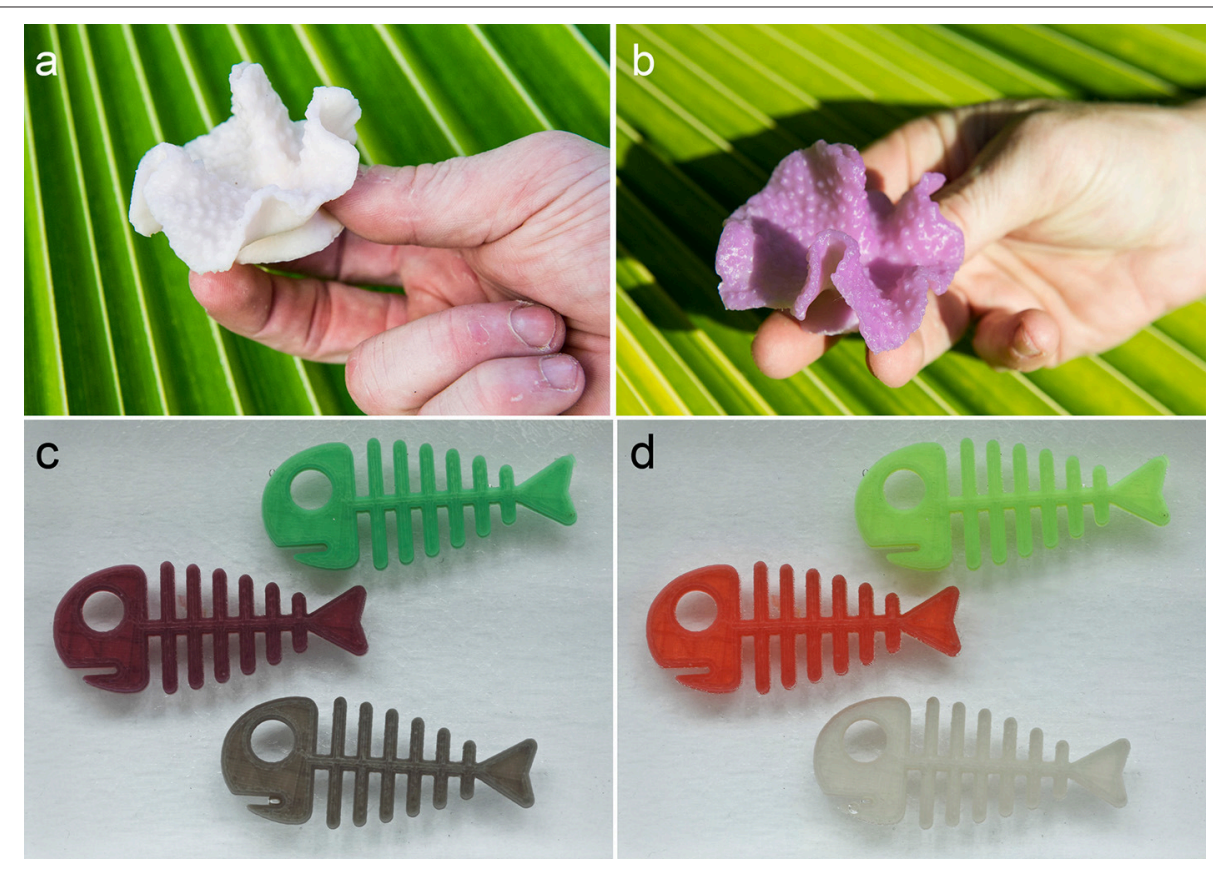

FIGURE 11 | Sensing materials for coral research. (a) Photochromic PLA 3D print of Turbinaria sp. skeleton. (b) Photochromic PLA 3D print of Turbinaria sp. skeleton under direct sunlight. (c) Thermochromic PLA 3D prints below $23^{\circ} \mathrm{C}$. (d) Thermochromic PLA $3 D$ prints above $23^{\circ} \mathrm{C}$.

and ceramics could potentially increase the recruitment rates of planulas and other reef organisms (https://www.popsci. com/3d-printing-could-save-coral-reefs, last accessed date: 18 January 2018). There is already a company specialising in the customisation and production of 3DP reef blocks (http:// www.reefdesignlab.com). The replication of reproduced coral structures, could also be utilised for the physical assessment of the factors impacting coral development, growth and destruction. 

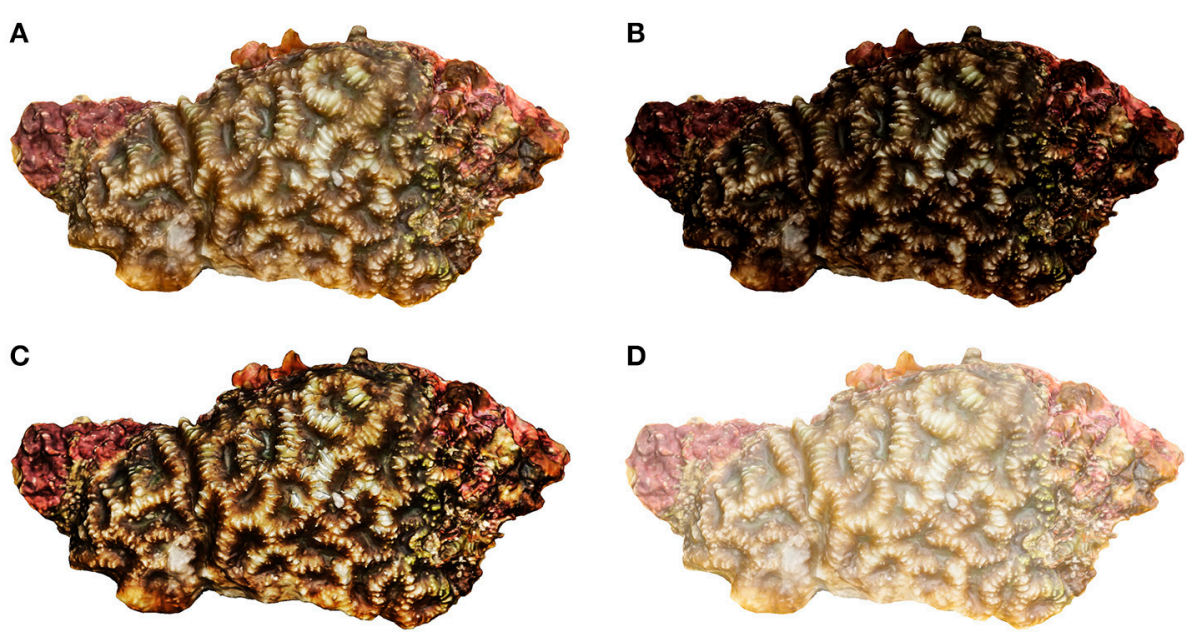

FIGURE 12 | Digital editing of model texture maps of Oulophyllia crispa fresh sample to highlight key features (Keaveney et al., 2016). (A) Light curve correction (B) Underexposed (C) High contrast (D) Overexposed.

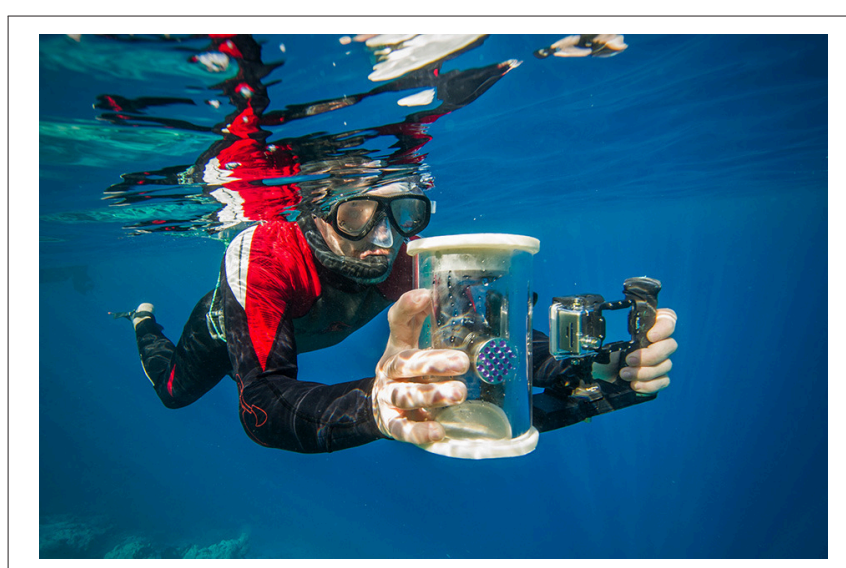

FIGURE 13 | Customised tools for coral research. 3D printed UV torch container and camera stabiliser used for field coral imaging.

These 3D prints could be used as replicas of real coral specimens in hydrodynamic simulations in flow chambers (Chindapol et al., 2013), allowing a greater understanding of the physical characteristics affecting coral degradation in the natural environment.

Education in taxonometric features and species identification can be greatly enhanced through the use of the proposed $3 \mathrm{DP}$ process. High resolution $3 \mathrm{D}$ printed specimen models with enhanced embodied taxonomic features can be used to highlight and aid in the identification of these features for educational purposes. Multi-scale printing of specific features, portions or appendages in these coral specimens, will allow greater understand of how different characteristics are related at distinct organisation levels, as seen previously in Figures 4, 5. These high definition multi-scale $3 \mathrm{D}$ prints were produced by previously embedding higher mesh resolution corallites into colony 3D meshes and segmenting them afterwards (Figure 14).
Similarly, multi-spectral (visible light, fluorescence, and infrared) specimens can also be produced, to help indicate the relationships present in coral communities at different electromagnetic spectra, and to show the relationship between their individual biological attributes, as seen in Figures 10, 11.

\section{DYI Coral Reef Research Tools}

3DP processes can also be utilised for the development and production of bespoke customised laboratory, workshop, and field tools for marine research activities. The ability to produce customised tools and accessories before field work and the possibility to produce replacement parts in the field using these systems can greatly increase the speed, specificity, quality and outcomes of field research (Baden et al., 2015). The open-source file depositories available inline allow these tools, pieces of equipment and concepts to be widely disseminated and quickly accessed, enabling their rapid customization, improvement and sharing in specialised and non-specialised online communities.

\section{A World of Opportunities...}

The rapid growth in popularity and subsequently development of the 3DP field, particularly in the consumer FDM space, has resulted in the development of a very wide spectrum of polymers compatible with low cost FDM systems. These new compatible materials include composites, such as PLA imbedded with particles such as copper, bronze, stainless steel, wood, ceramics, and carbon, all aimed at increasing the performance characterises of the end products, or other alternative biologically sourced materials made from wood, linen, lignin, or algae, to reduce the impact of oil derived polymers on the environment. These filaments offer differing degrees of texture, strength, flexibility, elasticity, and colour, including fluorescence, phosphorescence, and translucence (Figures 10, 11). These characteristics can be enhanced by selecting and editing a $3 \mathrm{D}$ model based on a specific digitising method, 


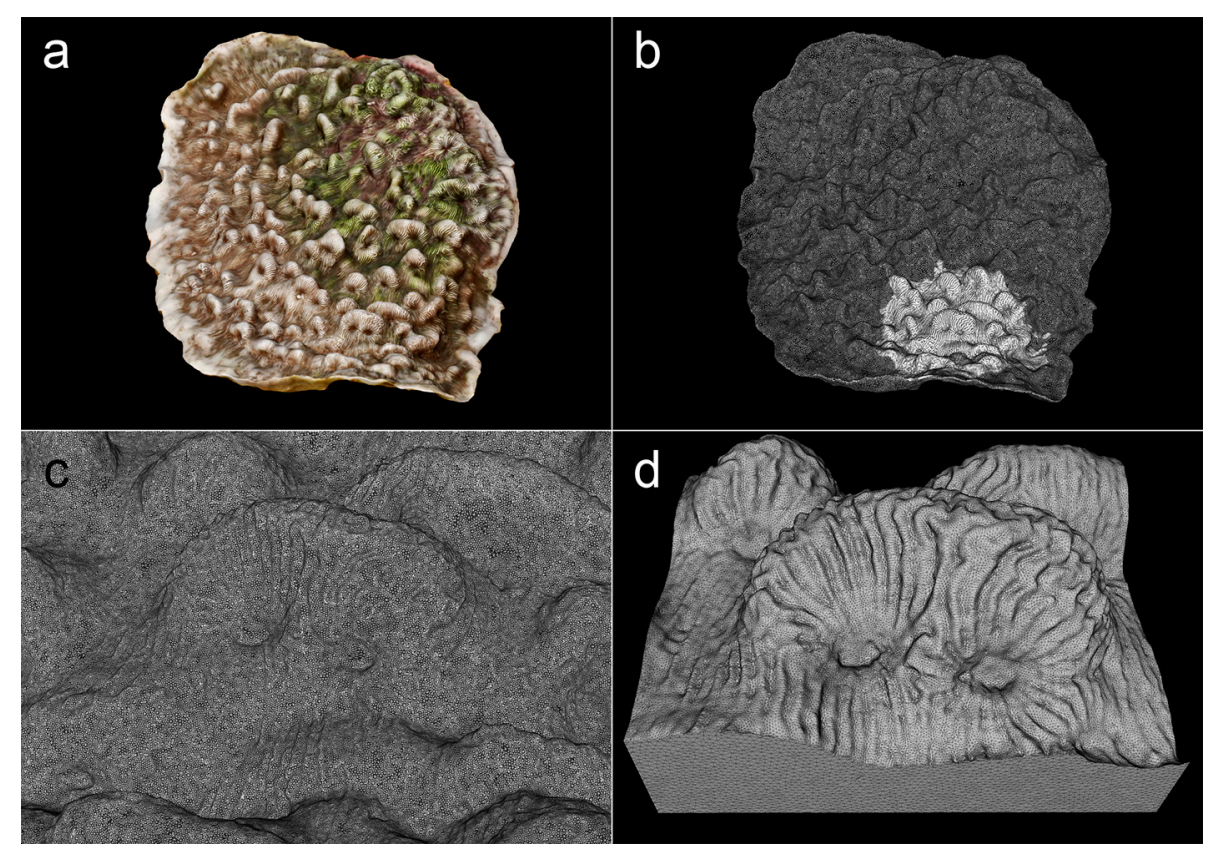

FIGURE 14 | Multi-scale 3D meshes of Leptoseris incrustans colony and corallites. (a) 3D model of colony with texture mapping. (b) 3D mesh of same colony, note the embedded corallites with higher triangle count on the lower side. (c) Close-up of portion of mesh with higher triangle count corallites. (d) Cropped corallites for 3D print.

or a fusion of different imaging technologies. 3D models produced from CT scans are highly detailed and accurate, even in microscopic samples, and produce meshes that display internal structures. These models were selected when translucent resins (SLA) could display internal anatomical details of coral samples and corallites (FDM). Likewise, these models could be potentially employed when producing $3 \mathrm{D}$ prints with plane cuts across the specimen to demonstrate internal structures with opaque materials (Figure 1B, and similar to Figure 10e). 3D models produced from photogrammetry were selected for also being highly detailed, accurate, and greatly inexpensive compared to CT scanning, and texture mapping can be used to produce coloured 3D prints of fresh samples (Binder jet and LOM).

An interesting approach to coral reef research, and general marine biology community research, would be the use of sensory materials, or reactive plastics, as discussed previously. Recent developments have made available polymer materials for FDM 3DP systems which are colour responsive to a range of changes in physicochemical parameters in the contact environment (Figure 11). Commercial sensory products with similar qualities have been used in aquariums to assist in keeping environmental parameters optimal (temperature, $\mathrm{pH}$, and UV light decals attached to the walls). Structures manufactured with these reactive polymers could be used on a larger scale in underwater environments. Thermochromic rings could be readily used to indicate abrupt changes in water temperature (e.g., El Nino climate incidents), photochrome rings could signal UV bleaching, and even halochromic rings could reveal changes in water acidity. These accessories are potential tools to passively monitor ocean changes using boats or permanently placed in environments, tools which could be easily monitored by locals without the need for specialist training or equipment.

Prospects for these technologies rely on the use of online resources to display, collaborate, and even add aesthetic and monetary value to the $3 \mathrm{DP}$ objects produced. One website, Sketchfab (https://sketchfab.com/therlab), allows the researcher to upload $3 \mathrm{D}$ content to a free account, where it can be displayed for education and science outreach, shared amongst collaborators, and even animated. Similarly, Thingiverse (https:// www.thingiverse.com/) and Shapeways (http://www.shapeways. $\mathrm{com} /$ ) can potentially be a marketplace where the users of $3 \mathrm{D}$ digitisation and $3 \mathrm{D}$ printing can promote a global community of design and manufacturing, increasing awareness, opportunities, and potential for the concept. Thingiverse is a free website aimed at the sharing of user created 3D design files, and Shapeways is a $3 \mathrm{D}$ printing forum and service start-up company. Used in conjunction, they provide a place where researchers can upload and share 3D printable files which can be printed in a wide range of materials and colours, then shipped across the globe. This allows for a multi-user community where valid $3 \mathrm{D}$ prints can be interchanged, and practical solutions and customised tools for research and monitoring can be produced.

These 3DP systems and their associated networks present huge potential for the replication and activation of coral analogues for research, education, and environmental protection, 
offering new methods to help protect these delicate marine communities.

\section{AUTHOR CONTRIBUTIONS}

LG-H: study's conception, article drafting, imaging; CK: article drafting, production of 3D prints for assessment; ER: study's conception, article drafting.

\section{REFERENCES}

Allard, T. T., Sitchon, M. L., Sawatzky, R., and Hoppa, R. D. (2005). "Use of handheld laser scanning and 3D printing for creation of a museum exhibit," in Proceedings of the 6th International Symposium on Virtual Reality, Archaeology and Cultural Heritage: Short and Project Papers, eds M. Mudge, N. Ryan, and R. Scopigno (Pisa), 97-101.

Baden, T., Chagas, A. M., Gage, G., Marzullo, T., Prieto-Godino, L. L., and Euler, T. (2015). Open labware: 3-d printing your own lab equipment. PLoS Biol. 13:e1002086. doi: 10.1371/journal.pbio.1002086

Chapman, H. P., Gaffney, V. L., and Moulden, H. L. (2010). The eton myers collection virtual museum. Int. J. Humanit. Arts Comput. 4, 81-93. doi: 10.3366/ijhac.2011.0009

Chindapol, N., Kaandorp, J. A., Cronemberger, C., Mass, T., and Genin, A. (2013). Modelling growth and form of the scleractinian coral pocillopora verrucosa and the influence of hydrodynamics. PLoS Comput. Biol. 9:e1002849. doi: 10.1371/journal.pcbi.1002849

Eisenberg, M. (2013). 3D printing for children: what to build next? Int. J. Child. Comput. Interact. 1, 7-13. doi: 10.1016/j.ijcci.2012.08.004

Eisenberg, M., and Buechley, L. (2008). Pervasive fabrication: making construction ubiquitous in education. J. Softw. 3, 62-68. doi: 10.4304/jsw.3.4.62-68

Fredieu, J. R., Kerbo, J., Herron, M., Klatte, R., and Cooke, M. (2015). Anatomical models: a digital revolution. Med. Sci. Educ. 25, 183-194. doi: 10.1007/s40670-015-0115-9

Gerstle, T. L., Ibrahim, A. M. S., Kim, P. S., Lee, B. T., and Lin, S. J. (2014). A plastic surgery application in evolution: three-dimensional printing. Plast. Reconstr. Surg. 133, 446-451. doi: 10.1097/01.prs.0000436844.92623.d3

Gutierrez-Heredia, L., Benzoni, F., Murphy, E., and Reynaud, E. G. (2016). End to end digitisation and analysis of three-dimensional coral models, from communities to corallites. PLoS ONE 11:e0149641. doi: 10.1371/journal.pone.0149641

Gutierrez-Heredia, L., D’Helft, C., and Reynaud, E. G. (2015). Simple Methods for interactive $3 \mathrm{D}$ modeling, measurements and digital databases of coral skeletons. Limnol. Oceanogr. Methods 13, 178-193. doi: 10.1002/lom3.10017

Jones, N. (2012). Science in tree dimensions: The print revolution. Nature 487, 22-23. doi: 10.1038/487022a

Keaveney, S., Keogh, C., Gutierrez-Heredia, L., and Reynaud, E. G. (2016). "Applications for advanced 3D imaging, modelling, and printing techniques for the biological sciences," in 22nd International Conference on Virtual System \& Multimedia (VSMM) (Kuala Lumpur), 1-8.

\section{ACKNOWLEDGMENTS}

We thank Julien Girardot during the Va'a Motu Workshop for photographs of sensing materials for coral research and the Fakarava community for their support. We also thank the dotation funds Explore-Roland Jourdain for supporting the Va'a Motu project and Air Tahiti Nui for their assistance. Help from the UCD College of Science is also greatly appreciated.

Klein, G. T., Lu, Y., and Wang, M. Y. (2013). 3D printing and neurosurgery-ready for prime time? World Neurosurg. 80, 233-235. doi: 10.1016/j.wneu.2013.07.009

Kodama, H. (1981). Automatic method for fabricating a three-dimensional plastic model with photo-hardening polymer. Rev. Sci. Instrum. 52, 1770-1773. doi: 10.1063/1.1136492

Kramer, A., Francour, P., Lescinski, J. M., Gautier-Debernardi, J., and Dini, E. (2016). "3D printed reefs as an enrichment for natural habitats," in Proceedings of the 13th International Coral Reef Symposium (Honololu, HI), 19-24.

Kuzminsky, S. C., and Gardiner, M. S. (2012). Three-dimensional laser scanning: potential uses for museum conservation and scientific research. J. Archaeol. Sci. 39, 2744-2751. doi: 10.1016/j.jas.2012.04.020

McGurk, M., Potamianos, P., Amis, A. A., and Goodger, N. M. (1997). Rapid prototyping techniques for anatomical modelling in medicine. Ann. R. Coll. Surg. Engl. 79:169-174.

Partridge, R., Conlisk, N., and Davies, J. A. (2012). In-lab three-dimensional printing. Organogenesis 8, 22-27. doi: 10.4161/org.20173

Rengier, F., Mehndiratta, A., von Tengg-Kobligk, H., Zechmann, C. M., Unterhinninghofen, R., Segerman, H. (2012). 3D Printing for mathematical visualisation. Math. Intell. 34, 56-62. doi: 10.1007/s00283-012-9319-7

Segerman, H. (2012). 3D Printing for mathematical visualisation. Math. Intell. 34, $56-62$.

Tomaka, A., Luchowski, L., and Skabek, K. (2009). "From Museum Exhibits to 3D Models," in Man-Machine Interactions, eds K. A. Cyran, S. Kozielski, J. F. Peters, U. Stanczyk, and A. Wakulicz-Deja (Berlin: AISC), 477-489.

Wachowiak, M. J., and Karas, B. V. (2009). 3D scanning and replication for museum and cultural heritage applications. JAIC 48, 141-158. doi: $10.1179 / 019713609804516992$

Conflict of Interest Statement: The authors declare that the research was conducted in the absence of any commercial or financial relationships that could be construed as a potential conflict of interest.

Copyright (c) 2018 Gutierrez-Heredia, Keogh and Reynaud. This is an open-access article distributed under the terms of the Creative Commons Attribution License (CC $B Y)$. The use, distribution or reproduction in other forums is permitted, provided the original author(s) and the copyright owner(s) are credited and that the original publication in this journal is cited, in accordance with accepted academic practice. No use, distribution or reproduction is permitted which does not comply with these terms. 